\title{
The Relationship between Cognitive Emotion Regulation and Job Stress: Moderating Role of Social Support
}

\author{
Ozgur Demirtas $^{1}$, Mahmut Ozdevecioglu ${ }^{2} \&$ Nejat Capar ${ }^{3}$ \\ ${ }^{1}$ 2nd Air Supply and Maintenance Center, TuAF, Kayseri, Turkey \\ ${ }^{2}$ Faculty of Economics and Administrative Sciences, Erciyes University, Kayseri, Turkey \\ ${ }^{3}$ Faculty of Economics and Administrative Sciences, Meliksah University, Kayseri, Turkey \\ Correspondence: Ozgur Demirtas (PhD), 2nd Air Supply and Maintenance Center, Kayseri, Turkey. Tel: \\ 90-505761-2148. E-mail: ozgurdemirtas@hvkk.tsk.tr
}

Received: December 19, 2014 Accepted: January 9, 2015 Online Published: April 30, 2015

doi:10.5539/ass.v11n12p168 URL: http://dx.doi.org/10.5539/ass.v11n12p168

\begin{abstract}
The present study examined the relationship between cognitive emotion regulation, social support and job stress. First, we investigated the relationship between cognitive emotion regulation and job stress. Second, we also have investigated that social support from work (peers or supervisors) and non-work (family or social networks) have a moderatoring effect on the relationship between cognitive emotion regulation and job stress. Based on a survey of 127 employees, we found support for our hypotheses that there is a negative relationship between cognitive emotion regulation and job stress. The results also show that work-related and non-work related social support positively moderates the relationship between cognitive emotion regulation and job stress. Results and implications are discussed and suggestions for future research are provided.
\end{abstract}

Keywords: cognitive emotion regulation, work related social support, non-work related social support, job stress

\section{Introduction}

The relationship between regulation and stress in the workplace is gaining closer attention in the literature. The ability and to control emotion is important for employees. Given the fact that humans in general and employees in specific live in a more stressful environment, it becomes essential to successfully regulate emotions. Emotions and emotion-based behavior is at the center of any social interaction. This is also true for social interactions at the workplace. Social interactions at the workplace don't always allow for the exhibition and expression of all the emotions an individual may have. The social context at work often requires the regulation of such experiences. Cognitive coping processes have been related to the experience and expression of emotions for a considerable time.

Perceived stress refers to how much stress an individual experiences as a function of a several factors such as stressful events, coping strategies, and personality differences. Stress, in general can be understood as a result of the interaction between the person and its environment. Individuals however, are not always at liberty to act upon their emotions (Grandey, 2003). Instead they are required to control their emotions while trying to cope with a variety of stressful events (Lazarus \& Folkman, 1984). Thus, a stressful environment requires emotion regulation skills.

In the present study, we are particularly interested in looking at the relationship between cognitive emotion regulation and job stress and at the moderating role of social support (Figure 1).

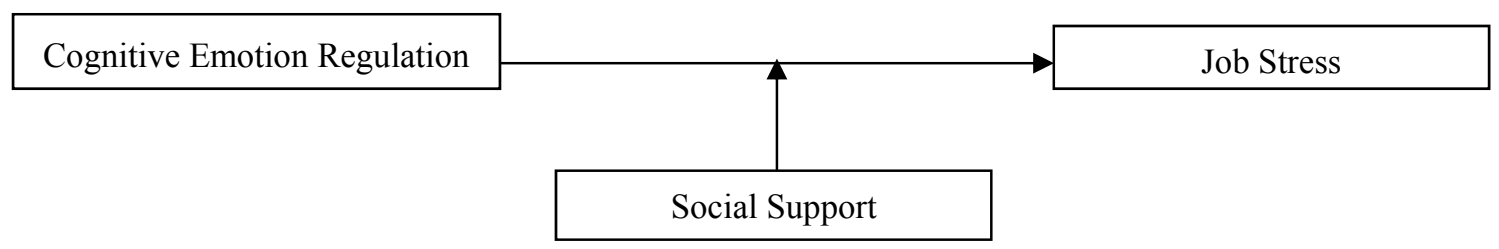

Figure 1. Model of the study 


\section{Literature Review}

Emotions refer to physiological arousal and cognitive appraisal of the situation (Grandey, 2000). Emotions arise when something important to us is at stake. Emotions often result in a coordinated set of behavioral, experiential, and physiological response tendencies that together influence how we respond to perceived challenges and opportunities (Gross, 2002). By regulating the arousal and cognitions that define emotions, individuals can control their emotional expressions to fit the display rules of the situation (Goffman, 1959).

\subsection{Cognitive Emotion Regulation and Job Stress}

Cognitive emotion regulation can be briefly defined as the management of emotions (Garnefski \& Kraaij, 2007; Thompson, 1991). It is considered as part of the broader concept of emotion regulation defined as "all the extrinsic and intrinsic processes responsible for monitoring, evaluating, and modifying emotional reactions, especially their intensive and temporal features" (Gross, 1999; Thompson, 1994). Research related to this topic has shown that emotion regulation by cognition is correlated with human life and it helps people to keep control over their emotions during or after the experience of threatening or stressful events (e.g., Garnefski et al., 2001; Garnefski, \& van den Kommer et al., 2002). This cognitive emotion regulation theory considers cognitive strategies in a conceptually pure way. Thus, it is separated from behavioral strategies in this manner (Garnefski et al., 2001; Garnefski et al., 2002; Garnefski \& Kraaij, 2006).

The Cognitive Emotion Regulation Questionnaire (CERQ) was developed by Garnefski, Kraaij, \& Spinhoven, (2001). It measures nine cognitive emotion regulation strategies on theoretical and empirical bases. Each strategy refers to what someone thinks after the experience of threatening or stressful events. The questionnaire has been used in a number of studies focusing on the relationships between cognitive emotion regulation strategies and stress; mental health; depression and anxiety. The strategies in this model are described as (Garnefski \& Kraaij, 2007); self-blame, other blame, rumination, catastrophizing, acceptance, putting into perspective, positive refocus, refocus on planning, and positive reappraisal.

Self-blame is described as the thoughts which put the blame that you have experienced on yourself. Other-blame is the opposite of the self-blame that you blame what you have experienced on the environment or another person. Rumination, which indicates to focusing on thought, is described as the thoughts or feelings associated with the negative events. Catastrophizing is described as the thoughts that emphasize the terror of what you have experienced. Acceptance is described as the thoughts that indicate resigning yourself to what has happened or thoughts of accepting what you have experienced. Putting into perspective is described as the thoughts of brushing aside the seriousness of the event/emphasizing the relativity when comparing it to other events. Positive refocusing emphasizes the joyful and pleasant thinking instead of actual event. Refocus on planning emphasizes the thoughts which indicate the taken steps to handle the negative events. The last one is positive reappraisal that refers to thoughts of creating a positive meaning to the event in terms of personal growth (Garnefski \& Kraaij, 2007).

There are some studies in the literature that mentioned the relationship between cognitive emotion regulation and stress (e.g., Carlson \& Perrewe, 1999; Garnefski et al., 2001; Garnefski et al., 2003; Garnefski \& Kraaij, 2006; Jermann et al., 2006; Kraaij et al., 2003). In the literature, social support has been emphasized as a solution to stressfull life events or organizational stress (Thomas \& Ganster, 1995). Lower levels of stress often result in content and satisfied employees, which in turn lead to an increased performance at work among other things. People, who have high levels of cognitive control over their emotions, are in effect marginalizing the influence of emotions. This way, cognitive emotional regulation absorbes some of the emotions that would be otherwise felt more substantially. In essence, the higher the ability is in which someone can regulate their emotions, the lesser the stress would be. Based on the arguments above, we pose the following hypothesis.

Hypothesis 1: Cognitive emotion regulation is negatively related to job stress.

\subsection{Social Support and Job Stress}

Social support refers to the exchange of resources between at least two persons, with the aim of helping the person who receives the support (House, 1981). Social support can be defined as resources available for others and important tools for coping with work-family conflict as they can mitigate the strain associated with stressors in different life domains. It can be provided in various ways that may include emotional concern as well as instrumental aid (House, 1981). The degree of support an employee receives is closely related to the level of stress one might experience in the workplace (Carlson \& Perrewe, 1999). Further, social support also leads to additional positive outcomes such as incresaed job satisfaction and incresead organizational identification (Parasuraman et al., 1992). 
Social support is divided into two parts. The first one indicating the work-related social support that emphasizes social support given from from supervisors or peers. This could positively enhance conditions of the work environment. A supportive supervisor, for example, may incease the fexibility and positiveness of the work conditions by showing concern for an employee's family related problems (Carlson \& Perrewe, 1999). The second type of social support is non-work related social support. Alternatively, social support provided outside the work could lead to reduction of work-family conflict (Burke, 1988). Family support has been shown to be an important factors in reducing work-nonwork conflict (Carlson \& Perrewe, 1999), while supportive social networks has been associated with lower levels of stress (Beutell \& Greenhaus, 1982; Carlson \& Perrewe, 1999; McCubbin et al., 1980). Various researches have considered social support as a moderating variable that enables reduced levels of stress (e.g., Ganster et al., 1986; Greenhaus \& Parasuraman, 1986; Fried \& Tiegs, 1993; Ray \& Miller, 1994).

Based on the discussion of the literature, we are interested to investigate the relationship between cognitive emotion regulation and job stress. Furthermore, we also wanted to see whether social support moderates the relationship between cognitive emotion regulation and job stress. Thus, we pose the following hypotheses;

Hypothesis 2a: Work related social support will moderate the relationship between cognitive emotion regulation and job stress.

Hypothesis 2b: Non-work related social support will moderate the relationship between cognitive emotion regulation and job stress.

\section{Method}

\subsection{Sample}

To test the stated hypotheses, a survey has been conducted to employees of an industrial organization in Kayseri, a city of Turkey. Participants of the survey had to be full-time employee of the organization in which the survey was conducted. Questionnaires were given to respondents in person in order to increase participation as well as to ensure accuracy. The researchers' presence allowed clarifying and misunderstandings related to the survey items. As a result of this approach we achieved a response rate close to $100 \%$, thus avoiding any possible non-response biases. In the final sample, there were 327 respondents. $71 \%$ of the respondents were male while $29 \%$ were female. The mean age was 41.3 years; while the average job experience with the organization was 11.2 years.

\subsection{Measures}

To asses Cognitive Emotion Regulation, the 36-item Cognitive Emotion Regulation Scale, which was improved by Garnefski \& Kraaij (2007), is used in this study. In addition, to assess the Work-related and Non-work related Social Support, we used the ten-item scale that was developed by Etzion (1984) and used by Carlson \& Perrewe, 1999. Seven of the items in work related social support correspond to the degree to which conditions such as appreciation and recognition is present in the workplace. The other three items correspond to the quality of the relationship subjects have with their supervisors, coworkers, and subordinates. In the non-work related social support scale, the seven items are similar to work related items but the final three items correspond to the quality of the relationship subjects have with their spouses, families, and friends.

Furthermore, to assess the Job Stress scale, which was developed by Howell et al. (1988), was taken from Maxwell et al. (2005). The scale has 3-items with a Cronbach's alpha values of .79, which is above the .70 level accepted as a reliable scale.

\section{Results}

The descriptive statistics showing the means, standard deviations and the correlations among the variables are given in Table 1. As can be seen, there are significant correlations between Cognitive Emotion Regulation, work related social support, non-work related social support and job stress.

Table 1. Mean, standard deviations and correlations

\begin{tabular}{lrrllll}
\hline Variable & Mean & SD & $\mathbf{1}$ & $\mathbf{2}$ & $\mathbf{3}$ & $\mathbf{4}$ \\
\hline 1. Cognitive Emotion Regulation & 3.27 & .91 & - & & & \\
2. Work Related Social Support & 3.19 & .87 & $.38^{* *}$ & - & & \\
3. Non-work Related Social Support & 3.09 & .81 & $.34^{* *}$ & $.49^{* *}$ & - & \\
4. Job Stress & 2.89 & 1.12 & $-.31^{* *}$ & $-.24^{* *}$ & $-.19^{*}$ & - \\
\hline
\end{tabular}

${ }^{*} \mathrm{p}<.05, * * \mathrm{p}<.01$ 
The correlations of the variables are all positive and don't seem to present any problems of multi-collinearity. Correlation statistics indicate that cognitive emotion regulation is negatively related to job stress $(\mathrm{r}=-.31 ; \mathrm{p}<.01)$. Also, as expected, there are negative correlations between job stress and work related social support $(\mathrm{r}=-.24$; $\mathrm{p}<.01)$; job stress and non-work related support $(\mathrm{r}=-.19 ; \mathrm{p}<.05)$.

The results for the hierarchical regression analyses are given in Table 2.

Table 2. Regression analyses for moderation

\begin{tabular}{|c|c|c|c|c|}
\hline & DV: Job Stress ( $\boldsymbol{\beta})$ & Adjusted $\mathrm{R}^{2}$ & $\Delta \mathrm{R}^{2}$ & F Change \\
\hline \multicolumn{5}{|l|}{ Model 1} \\
\hline Cognitive Emotion Regulation (CER) & $-.342 * *$ & .21 & .16 & $98.47 * *$ \\
\hline \multicolumn{5}{|l|}{ Model 2} \\
\hline Cognitive Emotion Regulation (CER) & $-.284 * *$ & & & \\
\hline Work Related Social Support (WSS) & $-.261 * *$ & .24 & .17 & $103.19 * *$ \\
\hline \multicolumn{5}{|l|}{ Model 3} \\
\hline Interaction (CER* WSS) & $.287 * *$ & 26 & .19 & $108.42^{* *}$ \\
\hline \multicolumn{5}{|l|}{ Model 2} \\
\hline Cognitive Emotion Regulation (CER) & $-.371 * *$ & & & \\
\hline Non-work Related Social Support (NWSS) & $-.227 * *$ & .19 & .11 & $86.02 * *$ \\
\hline \multicolumn{5}{|l|}{ Model 3} \\
\hline Interaction (CER* NWSS) & $.243 * *$ & .18 & .10 & $83.21 * *$ \\
\hline
\end{tabular}

$* \mathrm{p}<.05, * * \mathrm{p}<.01 ;$ Standardized betas are shown.

To test out hypotheses, we used regression in order to analyze the effects of our variables on the outcome variable "job stress". We used hierarchical regression to analyze the hypothesized relationships, whereby the independent variables were entered in to the regression model in separate stages.

Our first hypothesis predicted a negative correlation between cognitive emotion regulation, and stress. As predicted, results indicate a significant negative correlation between cognitive emotion regulation and stress, $\mathrm{r}=-.310, \mathrm{n}=127, \mathrm{p}<.01$. Examining the regresssion coefficient also shows support for Hypothesis 1 with a regression coefficient of $\beta=-.284(p<.01)$. In other words, the higher the cognitive emotion regulation is, the lower the stress level becomes. People who have the ability to cognitively control their emotions reducing the effects of outside events or behaviors so that it leads them to perceive less stress. In a way, cognitive emotional regulation acts as a filter mechanism that reduces the emotions felt due to arousals.

Our second hypothesis predicted that both work related (Hypothesis 2a) and non-work related (Hypothesis $2 b$ ) social support systems would moderate the relationship between cognitive emotional regulation. Results show that work-related and non-work related social supports moderate the relationship between cognitive emotional regulation and job stress.

As can be seen from Table 2, when the work related support (WSS) was entered into the model, the coefficient of cognitive emotional regulation became smaller, down from -.342 to -.284 , thereby clearly indicating a moderator relationship. Likewise, the interaction term (CESxWSS) is significant $(\beta=.287, \mathrm{p}<.01)$ indicating a postively moderated relationship. In other words, the effect of cognitive emotional regulation became smaller when there is work related support, which also helps to significantly reduce job stress $(\beta=-.261, \mathrm{p}<.01)$.

In contrast, when the work related support (NWSS) was entered into the model; the coefficient of cognitive emotional regulation became slightly greater, up from -.342 to -.371 , thereby clearly indicating a moderator relationship as well. In other words, the effect of cognitive emotional regulation became slightly greater when there is non-work related support, which also helps to significantly reduce job stress $(\beta=-.227, \mathrm{p}<.01)$. The interaction term (CESxNWSS) is also significant $(\beta=.243, \mathrm{p}<.01)$ indicating a postively moderated relationship.

Collectively, the results show support for Hypotheses $2 \mathrm{a}$ and $2 \mathrm{~b}$, providing evidence to the moderating role of social support. Based on the results, it can be said that the moderating effect of work-related social support is greater than the moderating effect of non-work related social support. While not hypothesized, both work related and non-work related social systems have an independent main effect on stress. That is, both types of social support systems lead to lower levels of job stress as can be seen in Table 2.

\section{Discussion and Conclusion}

This study investigated the effect of cognitive emotion regulation on job stress. Furthermore, we also examined the moderating role of social support on the relationship between cognitive emotion regulation on job stress. 
Cognitive emotion regulation (CER) directly and indirectly, through shaping work related and non-work related social supports, impacted individual's job stress. The results of this study are parallel to the literature findings (Greenhaus \& Parasuraman, 1986; Thomas \& Ganster, 1995; Garnefski, \& Kraaij, 2006).

Our results indicate that there is an important relationship between emotion regulation and stress. Stress is a critical issue for both employees and managers in an organization. Lower levels of stress often result in higher performing and satisfied employees. This, in turn has a positive effect on organizations because it leads to a better work environment with better results. To controll stress in the workplace may be achieved in various ways One method is that organizations provide such work conditions that will limit excessive stress. However, this may not be always the ideal situation as worklife may be full of stressors, despite the efforts by organizations to limit it. The ability to control and regulate emotions is a vital aspect of a productive work environment. Therefore, it is equally necessary for employees to have the capacity to regulate emotions in order to manage emotions and consequently stress. Organizations therefore have to pay attention during the recruitment stage to select employees who have the ability to manage and regulate their emotions among other things. Likewise, employee development programs can focus on enhancing such skills through workshops and training programs.

Another important aspect is the role of social support as these have a positive effect on reducing the stress of employees. Therefore, HRM functions in organizations must also focus on how to increase the levels of support both from work as well as from outside work. Providing mentors, among many others, is one example of an effective way to achieve this (Carlson \& Perewwe, 1999). Organizations also need to think about policies and programs that would foster a positive work-life balance that will allow for better family support, for example.

This study has several contributions to the literature. First, only full-time employees from all level of the organizations were surveyed in this study. Second, the survey has been administered by the researchers to increase participation and also to increase the accuracy of the responses. Third, this study advances the cognitive emotion regulation literature, by examining the effects of cognitive emotion regulation on job stress. We have shown that both cognitive emotion regulation and social support has a positive effect on reducing stress. These findings have important implications for the literature as well as for practice.

There are also several limitations in this study that need to be highlighted in order to place the findings in the appropriate context. First, the sample was obtained from a single organization and therefore not demographically diverse. Of course, this also allowed us to control for factors that might differ from organization to organization. However, on the downside, it limits the generalization of the results to a larger context. Further, our study was based on a cross-sectional design. Thus, future research should focus on longitudinal research designs in order to minimize the common method variance. This will allow for better control of temporal effects as well as of relationships observed that are not being able to distinguished more clearly.

The findings of this study have shown that relationships do exist between cognitive emotion regulation and job stress. However, further research is needed to examine more closely the complexities of these relationships. Future research can extend this study's results by including constructs such as organizational commitment \& citizenship behavior, job satisfaction and job performance in their research models. This will allow for a more comprehensive understanding among the variables mentioned and their relationship to cognitive emotional regulation and stress.

\section{References}

Beutell, N. J., \& Greenhaus, J. H. (1982). Interrole conflict among married women: The influence of husband and wife characteristics on conflict and coping behavior. Journal of Vocational Behavior, 21, 99-110.

Burke, R. J. (1988). Some antecedents and consequences of work-family conflict. In E. Goldsmith (Ed.), Work and Family: Theory, Research and Applications. Journal of Social Behavior and Personality, 34, 287-302.

Carlson, D. W., \& Perrewe, P. L. (1999). The role of social support in the stressor-strain relationship: An examination of work-family conflict. Journal of Management, 25(4), 513-540.

Fried, Y., \& Tiegs, R. B. (1993). The main effect model versus buffering model of shop steward social support: A study of rank-in-file auto workers in the USA. Journal of Organizational Behavior, 14, 483-488.

Ganster, D. C., Fusilier, M. R., \& Mayes, B. T. (1986). Role of social support in the experience of stress at work. Journal of Applied Psychology, 71, 102-110. http://dx.doi.org/10.1037/0021-9010.71.1.102

Garnefski, N., \& Kraaij, V. (2006). Relationships between cognitive emotion regulation strategies and depressive symptoms: A comparative study of five specific samples. Personality and Individual Differences, 40, 1659-1669. http://dx.doi.org/10.1016/j.paid.2005.12.009 
Garnefski, N., \& Kraaij, V. (2007). The cognitive emotion regulation questionnaire. European Journal of Psychological Assessment, 23(3), 141-149. http://dx.doi.org/10.1027/1015-5759.23.3.141

Garnefski, N., Kraaij, V., \& Spinhoven, P. (2001). Negative life events, cognitive emotion regulation and depression. Personality and Individual Differences, 30, 1311-1327.

Garnefski, N., Teerds, J., Kraaij, V., Legerstee, J., \& van den Kommer, T. (2003). Cognitive emotion regulation strategies and depressive symptoms: Differences between males and females. Personality and Individual Differences, 36, 267-276. http://dx.doi.org/10.1016/S0191-8869(03)00083-7

Garnefski, N., van den Kommer, T., Kraaij, V., Teerds, J., Legerstee, J., \& Onstein, E. (2002). The relationship between cognitive emotion regulation strategies and emotional problems. European Journal of Personality, 16, 403-420. http://dx.doi.org/10.1002/per.458

Goffman, E. (1959). The presentation of self in everyday life.

Gore, S. (1987). Perspectives on social support and research on stress moderating processes. In J. M. Ivancevich, \& D. C. Ganster (Eds.), Job stress: From theory to suggestion. New York: Haworth Press.

Grandey, A. A. (2000). Emotion regulation in the workplace: A new way to conceptualize emotional labor. Journal of Occupational Health Psychology, 5(1), 95-110. http://dx.doi.org/10.1037/1076-8998.5.1.95

Grandey, A. A. (2003). When "The show must go on": Surface acting and deep acting as determinants of emotional exhaustion and peer-rated service delivery. Academy of Management Journal, 46(1), 86-96.

Greenhaus, J., \& Parasuraman, S. (1986). A work-nonwork interactive perspective of stress and its consequences. In J. M. Ivancevich, \& D. C. Ganster (Eds.), Job Stress: From Theory to Suggestion. Haworth Press.

Gross, J. J. (1999). Emotion regulation: Past, present, future. Cognition and Emotion, 13, 551-573.

Gross, J. J. (2002). Emotion regulation: Affective, cognitive, and social consequences. Psychophysiology, 39 281-291. http://dx.doi.org/10.1017/S0048577201393198

House, G. S. (1981). Work stress and social support. Reading, MA: Addison-Wesley.

Jermann, F., Van der Linden, M., d'Acremont, M., \& Zermatten. (2006). Cognitive Emotion Regulation Questionnaire (CERQ): Confirmatory factor analysis and psychometric properties of the French translation. European Journal of Psychological Assessment, 22, 126-131. http://dx.doi.org/10.1027/1015-5759.22.2.126

Kraaij, V., Garnefski, N., Wilde, E. J. de, Dijkstra, A., Gebhardt, W., Maes, S., \& Doest, L. (2003). Negative life events and depressive symptoms in late adolescence: Bonding and cognitive coping as vulnerability factors? Journal of Youth and Adolescence, 32, 185-193. http://dx.doi.org/10.1023/A:1022543419747

Lazarus, R. S., \& Folkman, S. (1984). Stress, appraisal and coping. New York, NY: Springer Publishing Co.

Maxwell, S., Reed, G., Saker, J., \& Story, V. (2005). The two faces of playfulness: A new tool to select potentially successful sales reps. Journal of Personal Selling \& Sales Management, 25(3), 215-229.

McCubbin, H., Joy, C., Cauble, A., Comeau, J., Patterson, J., \& Needle, R. (1980). Family stress and coping: A decade review. Journal of Marriage and the Family, 42, 855-871. http://dx.doi.org/10.2307/351829

Parasuraman, S., Greenhaus, J. H., \& Granrose, C. S. (1992). Role stressors, social support, and well-being among two-career couples. Journal of Organizational Behavior, 13, 339-356.

Ray, E. B., \& Miller, K. I. (1994). Social support, home/work stress, and burnout: Who can help? Journal of Applied Behavioral Science, 30, 357-373. http://dx.doi.org/10.1177/0021886394303007

Thomas, L. T., \& Ganster, C. D. (1995). Impact of family-supportive work variables on work-family conflict and strain: A control perspective. Journal of Applied Psychology, 80, 6-15.

Thompson, R. A. (1991). Emotional regulation and emotional development. Educational Psychology Review, 3, 269-307. http://dx.doi.org/10.1007/BF01319934

Thompson, R. A. (1994). Emotional regulation: A theme in search for definition. Monographs of the Society for Research in Child Development, 59, 25-52. http://dx.doi.org/10.2307/1166137

\section{Copyrights}

Copyright for this article is retained by the author(s), with first publication rights granted to the journal.

This is an open-access article distributed under the terms and conditions of the Creative Commons Attribution license (http://creativecommons.org/licenses/by/3.0/). 